\title{
Laser induced calcium oscillations in fluorescent calcium imaging
}

\author{
János Vincze ${ }^{1, \star}$, Nikolett Geyer ${ }^{1, \star}$, Gyula Diszházi ${ }^{1}$, László Csernoch ${ }^{1}$, Tamás Bíró ${ }^{2}$, István Jóna ${ }^{1}$, \\ Beatrix Dienes ${ }^{1}$ and János Almássy ${ }^{1}$ \\ ${ }^{1}$ Department of Physiology, University of Debrecen, Faculty of Medicine, 98. Nagyerdei krt., Debrecen 4012, Hungary \\ ${ }^{2}$ Departments of Immunology, University of Debrecen, Faculty of Medicine, 98. Nagyerdei krt., Debrecen 4012, Hungary
}

\begin{abstract}
Phototoxicity is the most common problem investigators may encounter when performing live cell imaging. It develops due to excess laser exposure of cells loaded with fluorophores and can lead to often overlooked but significant artifacts, such as massive increase of intracellular $\mathrm{Ca}^{2+}$ concentration, which would make data interpretation problematic. Because information about laser- and dye-related changes in cytoplasmic calcium concentration is very limited, we aimed to describe this phenomenon to help investigators using laser scanning confocal microscopy in a non-invasive way. Therefore, in the present study we evaluated fluorescent fluctuations, which evolved in Fluo-3/4/8 loaded mouse pancreatic acinar cells during very low intensity laser excitation. We demonstrate that after standard loading procedure ( $2 \mu \mathrm{M}$ Fluo-3/4/8-AM, $30 \mathrm{~min}$ at room temperature), applying $488 \mathrm{~nm}$ laser at as low as ca. $10 \mu \mathrm{W}$ incident laser power $\left(0.18 \mu \mathrm{W} / \mu \mathrm{m}^{2}\right)$ at $1 \mathrm{~Hz}$ caused repetitive, 2-3 fold elevations of the resting intracellular fluorescence. The first latency and the pattern of the fluorescence fluctuations were laser power dependent and were related to $\mathrm{Ca}^{2+}$-release from intracellular stores, as they were abolished by BAPTA-AM treatment in $\mathrm{Ca}^{2+}$-free medium, but were not diminished by the reactive oxygen species (ROS) scavenger DMPO. Worryingly enough, the qualitative and quantitative features of the $\mathrm{Ca}^{2+}$-waves were practically indistinguishable from the responses evoked by secretagogue stimulation. Since using similar imaging conditions, a number of other cell types were reported to display spontaneous $\mathrm{Ca}^{2+}$ oscillations, we propose strategies to distinguish the real signals from artifacts.
\end{abstract}

Abbreviations: $\left[\mathrm{Ca}^{2+}\right]$, intracellular calcium concentration; BSA, bovine serum albumin; cch, carbachol; CICR, calcium-induced calcium release; ER, endoplasmic reticulum; $\mathrm{IP}_{3} \mathrm{R}$, inositol trisphosphate receptor; ROI, region of interest; ROS, reactive oxygen species; RyR, ryanodine receptor; SERCA, sarco-endoplasmic reticulum calcium ATP-ase; SOCE, store-operated calcium entry.

\section{Introduction}

$\mathrm{Ca}^{2+}$ is an important second messenger in the cell, which controls many cellular functions such as muscle contraction, exocytosis, gene expression, proliferation and

Electronic supplementary material. The online version of this article (doi: 10.4149/gpb_2017054) contains supplementary material which is available to authorized users.

Correspondence to: János Almássy, Department of Physiology, University of Debrecen, Faculty of Medicine, 98. Nagyerdei krt., Debrecen 4012, Hungary

E-mail: almassy.janos@med.unideb.hu

* These authors contributed equally to this work. cell death. In order to fulfill its mission, it is essential to maintain intracellular $\mathrm{Ca}^{2+}$ concentration $\left(\left[\mathrm{Ca}^{2+}\right]_{\mathrm{i}}\right)$ low at rest, but to allow it rapidly and transiently rise during excitation. For example, in pancreatic acinar cells $\left[\mathrm{Ca}^{2+}\right]_{\mathrm{i}}$ is elevated by $\mathrm{Ca}^{2+}$-release from the endoplasmic reticulum (ER) through inositol trisphosphate receptors $\left(\mathrm{IP}_{3} \mathrm{R}\right)$ and ryanodine receptors (RyR) upon secretagogue stimulation to trigger exocytosis of zymogen containing vesicles (Williams et al. 1978; Habara et al. 1994; Straub et al. 2000; Leite et al. 2002; Petersen et al. 2007). Sustained stimulation leads to ER depletion and the activation of store-operated calcium entry (SOCE) to support prolonged $\mathrm{Ca}^{2+}$ signals and ER reload (Lewis et al. 2007; Putney et al. 2007; Smyth et al. 2010). Afterwards, $\left[\mathrm{Ca}^{2+}\right]_{i}$ is restored by the sarcoendoplasmic reticulum $\mathrm{Ca}^{2+}$-ATP-ase (SERCA) and the 
plasma membrane $\mathrm{Ca}^{2+}$ pump (PMCA). They are also responsible for keeping $\left[\mathrm{Ca}^{2+}\right]_{\mathrm{i}}$ stable and low $(\mathrm{ca} .100 \mathrm{nM})$ in unstimulated cells (Yule 2010).

Certainly, biomedical researchers are particularly interested in measuring the changes of $\left[\mathrm{Ca}^{2+}\right]_{i}$ because of its critical influence on the cell's fate. Their scientific ambition is supported by the development of fluorescent $\mathrm{Ca}^{2+}$ imaging techniques in the past few decades. The simplest and most popular $\mathrm{Ca}^{2+}$ imaging tools are the $\mathrm{Ca}^{2+}$ indicator fluorescent dyes from the Fluo family (Fluo-3/4/8) (Minta et al. 1989; Gee et al. 2000). These dyes are also available in acetoxymethylester (AM)-conjugated form which easily cross the plasma membrane, but inactive (does not bind $\mathrm{Ca}^{2+}$ ). The dye attains activity after the AM group is enzymatically hydrolyzed by intracellular esterases, which also makes the resulting dye water soluble to prevent the dye escaping from the cell.

An important problem of fluorescent imaging is that exposure of the fluorophore to high intensity focused light is required for excitation and subsequent fluorescent emission; however, the illuminating light itself is the source of two undesirable consequences: phototoxicity and photobleaching (Rohrbach et al. 2005; Pawley et al. 2006; Hoebe et al. 2007; Bootman et al. 2013; Collins et al. 2014). Photobleaching (fading) is mainly due to classic photodestruction, whereas phototoxicity is due to the photochemical reaction of the excited fluorophore with molecular oxygen, which produces reactive oxygen species (ROS). ROS oxidize cellular components that results in cell damage (phototoxicity), and also react with the fluorophore, which contributes to fluorescent signal loss (photobleaching) (Rohrbach et al. 2005; Pawley et al. 2006; Hoebe et al. 2007; Bootman et al. 2013; Collins et al. 2014). The major complication of phototoxicity during live cell imaging is not the reduced cell viability itself, but the unusual behavior of the damaged cell, which can contaminate the detected signal and deceive the investigator (Rohrbach et al. 2005; Pawley et al. 2006; Hoebe et al. 2007; Bootman et al. 2013; Collins et al. 2014).

An example of such an artifact is light-induced $\mathrm{Ca}^{2+}$ elevation in cells loaded with Fluo-calcium sensitive dyes. While this issue could affect most of the confocal microscopy users who perform $\mathrm{Ca}^{2+}$ imaging, its literature is limited to only a couple of papers (Knight et al. 2003; McDonald et al. 2012). These reports describe light-induced $\mathrm{Ca}^{2+}$ transients in Fluo3 AM-loaded smooth muscle cells and in Fluo-4 AM-loaded cultured chondrocytes during epifluorescent imaging using light emitting diodes and during laser-scanning confocal microscopy, respectively. In the present paper repetitive, laser activated $\mathrm{Ca}^{2+}$-release events were evaluated in Fluoloaded pancreatic acinar cells and other cell types using laser scanning confocal microscopy to help investigators identify light-related artifacts. Moreover, strategies to overcome the problem are also offered.

\section{Materials and Methods}

\section{Chemicals}

Fluo-3/4/8-AM and Fura-Red-AM was purchased from Molecular Probes (ThermoFisher Scientific). All other materials were purchased from Sigma, unless otherwise specified.

\section{Pancreatic acinar cell isolation}

Experiments were performed in accordance with EU (86/609/EEC) guideline under a license obtained from the Scientific Committee on Animal Health and Welfare of the University of Debrecen. Pancreatic acinar cells were freshly isolated from mouse pancreas as described previously. Briefly, 2-4 months old NMRI mice of both genders were euthanized by cervical dislocation and the pancreas was rapidly removed. The tissue was injected with F12/DMEM medium containing $100 \mathrm{U} / \mathrm{ml}$ collagenase $\mathrm{P}$ (Roche), $0.1 \mathrm{mg} / \mathrm{ml}$ trypsin inhibitor and $2.5 \mathrm{mg} / \mathrm{ml} \mathrm{BSA}$ and then incubated in this solution for 30 minutes in a $37^{\circ} \mathrm{C}$ shaking water bath. The media were continuously gassed with carbogen. The tissue was dissociated by pipetting 4-6 times using a $5 \mathrm{ml}$ serological pipette. The cell clumps then were filtered through mesh \#60 $(150 \mu \mathrm{m})$. The filtrate was layered on the top of $400 \mathrm{mg} / \mathrm{ml} \mathrm{BSA}$ and washed through the medium by gentle centrifugation. The cell pellet was resuspended and collected by centrifugation. Acinar cell clumps were gently resuspended in F12/DMEM medium and kept gassed at room temperature until use (Geyer et al. 2015).

\section{Cell cultures}

HEK293 cells and HaCaT keratinocytes were cultured in DMEM medium supplemented with $10 \%$ fetal bovine serum (FBS) at $37^{\circ}$ in a $\mathrm{CO}_{2}$ thermostat (Geyer et al. 2015). Cells were allowed to grow to $60-70 \%$ confluence.

\section{Intracellular $\mathrm{Ca}^{2+}$ imaging}

Acinar cell clumps and other cell cultures were loaded with 0.5-2 $\mu \mathrm{M}$ Fluo-4-AM Ca ${ }^{2+}$-sensitive dye for 30 minutes at room temperature (exact concentrations used are indicated in the text). Cells were plated on glass coverslips and mounted on a perfusion chamber. After perfusion with Tyrode's solution containing (in $\mathrm{mM}$ ): $140 \mathrm{NaCl}, 5 \mathrm{KCl}, 2 \mathrm{MgCl}_{2}$ and 10 HEPES, $\mathrm{pH}=7.2$ with or without $1.8 \mathrm{CaCl}_{2}$, fluorescence was monitored in time series measurements using a Zeiss LSM 5 LIVE confocal microscope equipped with a $40 \times$ oil immersion objective for most experiments or a Zeiss LSM 510 META confocal microscope with a similar objective for some experiments. Fluo- 4 was excited at $488 \mathrm{~nm}$ and the emitted light was collected through a 500-525 $\mathrm{nm}$ band-pass filter. 
The pinhole was set to correspond to ca. $5 \mu \mathrm{m}$ tissue section widths (Geyer et al. 2015). In some experiments Fluo-4-AM was co-loaded with Fura-Red AM ( 2 and $6 \mu \mathrm{M}$ respectively). In these experiments, both fluorophores were excited with the $488 \mathrm{~nm}$ argon laser, the emitted light was divided by a $635 \mathrm{~nm}$ beamsplitter and detected simultaneously after filtered with a 500-525 nm bandpass filter for the green channel or no filter for the red channel. In some experiments, cells were treated with $20 \mu \mathrm{M}$ BAPTA AM for 20 minutes or $2 \mathrm{mM}$ tetracaine (tetracaine was also included in the perfusion solution). To test the role of ROS, $500 \mu \mathrm{M}$ 5,5-dimethyl-pyrroline $\mathrm{N}$-oxide (DMPO) was included into the bath solution $(\mathrm{pH}=7.2)$. Fluorescence emission data of single cells was analyzed and F/F0 ratio was calculated after background subtraction using Zeiss ZEN 2009 and Microsoft Excel software, respectively. Spatio-temporal analysis of $\mathrm{Ca}^{2+}$ waves was performed using high frequency line-scan imaging (500 lines/s).

\section{Statistics}

Averages are expressed as mean \pm SEM (standard error of the mean). Statistical analysis was performed using Student's $t$-test. Threshold for statistically significant differences as compared to the respective control was set at ${ }^{\star} p<0.01$.

\section{Results}

\section{Spontaneous $\mathrm{Ca}^{2+}$ oscillations observed in $x-y$ imaging} mode

The data presented here were obtained in enzymatically isolated mouse pancreatic acinar cell clumps of various sizes (ca. 10-30 cells) using a Zeiss LSM 5 LIVE line-scanning confocal microscope. The cells showed retained polarized morphology, characterized by apical granules. The cell clumps maintained typical acinar architecture. No obvious signs of cell damage (e.g. blebbing) were observed either before or after the experiments (Figure 1A). Importantly, we intended to avoid phototoxicity by optimizing the dye loading conditions so the resting fluorescence fell above the lowest measurable intensity. Using $1 \mathrm{~mW}$ laser power output, the resting intracellular fluorescence ( $872 \pm 72$ arbitrary unit, AU) was only 3 fold higher than the background fluorescence (288 $\pm 14 \mathrm{AU})$. Notably, this laser intensity corresponds to only $1 \%$ of the maximum power output of our argon laser, which is a typical setting for confocal imaging of live cells. In this case, due to various losses in the imaging system, $10 \mu \mathrm{W}$ laser power is transmitted through the objective and the power density of the light is $0.18 \mu \mathrm{W} / \mu \mathrm{m}^{2}$ and the dwell time is $972 \mu \mathrm{s}$.

Acinar cells were loaded with $2 \mu \mathrm{M}$ Fluo-4-AM for 30 minutes and mounted on coverslips of a perfusion chamber. Cells were washed with physiological saline solution and were excited repetitively with a $488 \mathrm{~nm}$ laser beam at 1 $\mathrm{mW}, 1 \mathrm{~Hz}$ using the $\mathrm{x}-\mathrm{y}$ scan mode. Because unstimulated acinar cells should exhibit stable basal $\left[\mathrm{Ca}^{2+}\right]_{\mathrm{i}}$ (Petersen et al. 2007), we were surprised to observe robust, repetitive fluctuations of intracellular fluorescence in most of the cells, which appeared within 3 minutes after the first frame and rapidly expanded in the whole cell. Fluorescence seemed to increase in most cells of the specimen. An example of such a fluorescence oscillation is shown in Figure 1B.

Although, a number of cell types (Fedoryak et al. 2004; Johnston et al. 2005; Wang et al. 2006; Vukcevic et al. 2010) were shown to display physiologically relevant spontaneous $\mathrm{Ca}^{2+}$ oscillations, resting oscillatory behavior is not the intrinsic property of acinar cells, which suggest that what we have seen was a light-induced artifact. One would expect light-induced artifacts to be dependent on exciting light intensity and other imaging conditions. In contrast, if our oscillations were due to spontaneous, intrinsic biological activity of the cell, it wouldn't be laser power dependent. Therefore, we aimed to find out how this phenomenon could have triggered and to test its light dose-response relationship.

The oscillations apparently had a dye-related origin, as they had earlier onset and higher amplitude at higher dye concentrations and could be completely prevented by using lower extracellular Fluo-4-AM concentrations. Also, our experiments using different laser powers demonstrated that the qualitative features of the fluorescence highly depended on the laser exposure. In comparison with $1 \mathrm{~mW}$, at $3 \mathrm{~mW}$ (ca. $30 \mu \mathrm{W}$ incident light, $0.54 \mu \mathrm{W} / \mu \mathrm{m}^{2}$ power density) we detected long-lasting elevations of the fluorescence with depressed oscillatory behavior and earlier onset, but similar spiking frequency $(0.99 \pm 0.03 / \mathrm{min} v s .0 .95 \pm 0.08 / \mathrm{min}$, Figure $1 \mathrm{~B}-\mathrm{F}$ ). The first peak latency of fluorescence was $237 \pm 6 \mathrm{~s}$ for $1 \mathrm{~mW}$ and $140 \pm 13 \mathrm{~s}$ for $3 \mathrm{~mW}$ (Figure 1E). Although, most of the cells responded to both laser intensities, the ratio of active cells varied between specimens, with $>90 \%$ in some cases. However, when cells were imaged using lower laser power $(0.5 \mathrm{~mW}$ laser output $=5 \mu \mathrm{W}$ incident light power and $0.09 \mu \mathrm{W} / \mu \mathrm{m}^{2}$ power density) at $0.5 \mathrm{~Hz}$, fluorescence was stable during the 12 minutes recording time except for the insignificant, but continuous reduction of basal fluorescence, because of photobleaching (Figure 1D). Very similar oscillatory behavior was demonstrated in Fluo-3 and Fluo-8 loaded pancreatic acinar cells, too (supplementary Figure S1.).

Our biggest concern about the phenomenon was that the light-activated oscillatory behavior was practically indistinguishable from the activity elicited by the parasympathic neurotransmitter acetylcholin-analogue carbachol (cch), which we often use to test pancreatic acinar cell function. This is demonstrated in Figure 1G, which shows a typical response of acinar cells to 100 and $200 \mathrm{nM}$ cch under "non-invasive" imaging conditions (i.e. $0.5 \mathrm{~mW}$ laser power, $0.5 \mathrm{~Hz}$ ). These original records clearly show that the signal 
amplitude and the oscillation frequency were very similar for the cch and the laser-induced signals.

To exclude the possibility that the oscillations can be only elicited by our Zeiss LSM 5 LIVE line-scanning high-speed confocal microscope, similar experiments were performed using a Zeiss LSM 510 META microscope. Similar spontaneous repetitive fluorescence spikes could have been also observed (supplementary Figure S2.).

\section{$\mathrm{Ca}^{2+}$ oscillations in HEK293 cells and HaCaT keratinocytes}

In order to determine whether this artefact is restricted to pancreatic acinar cells or occurs in other cell types too, we performed similar experiments using Fluo-4-AM loaded HEK293 cells and HaCaT keratinocytes. Both cell types showed similar spontaneous transient elevation of $\left[\mathrm{Ca}^{2+}\right]_{\mathrm{i}}$ (Figure 2A and $\mathrm{B}$ ). Interestingly, no transients could be triggered again on the same cells using the same imaging conditions.

Detailed investigation and prevention of spontaneous $\mathrm{Ca}^{2+}$ oscillations in pancreatic acinar cells

Next, in order to prevent the spontaneous calcium oscillations, we aimed to learn more about them. In previous studies, ROS production was shown to be responsible for
A

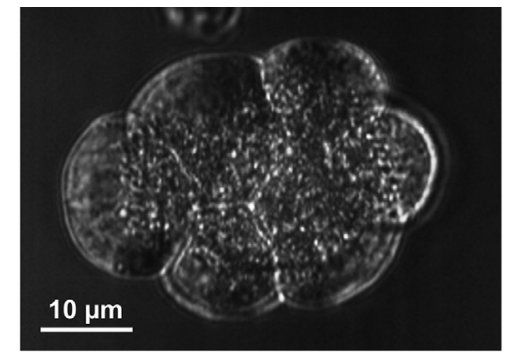

B

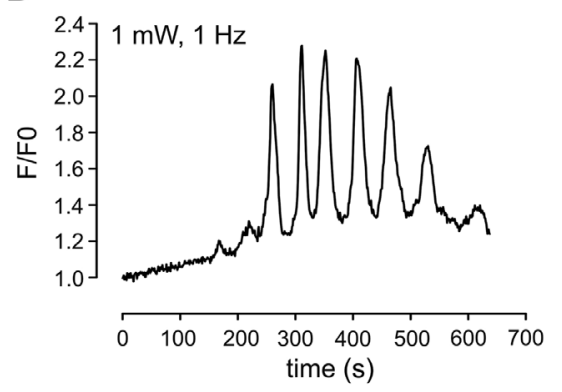

C

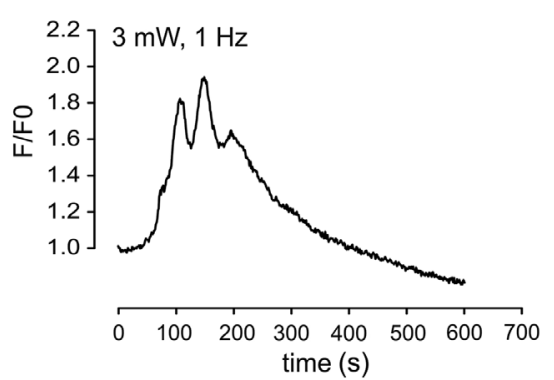

D

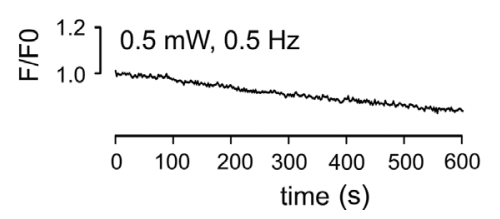

E

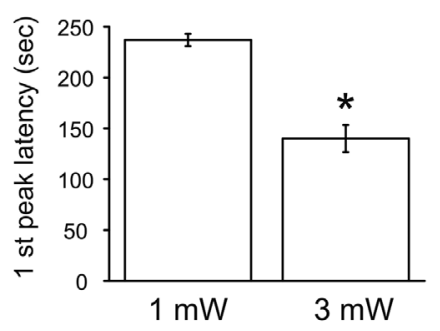

F

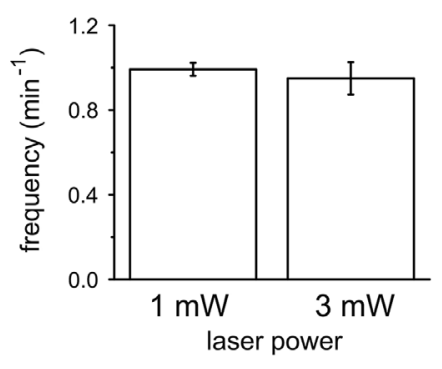

G

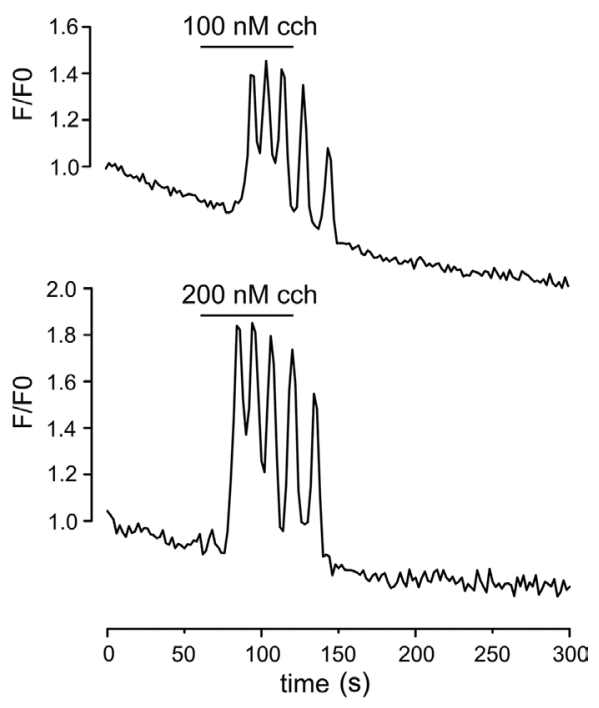

Figure 1. Features of laserinduced changes of Fluo-4 fluorescence in pancreatic acinar cells. A. Bright-field microscopy image of a pancreatic acinar cell clump. Representative time series fluorescent records of Fluo-4 loaded single acinar cells using $1 \mathrm{~mW}$ (B), $3 \mathrm{~mW}$ (C) and 0.5 $\mathrm{mW}$ (D) laser power settings. E. Laser power dependence of the latency of the first fluorescence peak $\left({ }^{\star} p<0.01\right)$. F. Laser power dependence of the frequency of fluorescent oscillation. G. Carbachol (cch)-induced $\mathrm{Ca}^{2+}$ oscillations in single pancreatic acinar cells. 

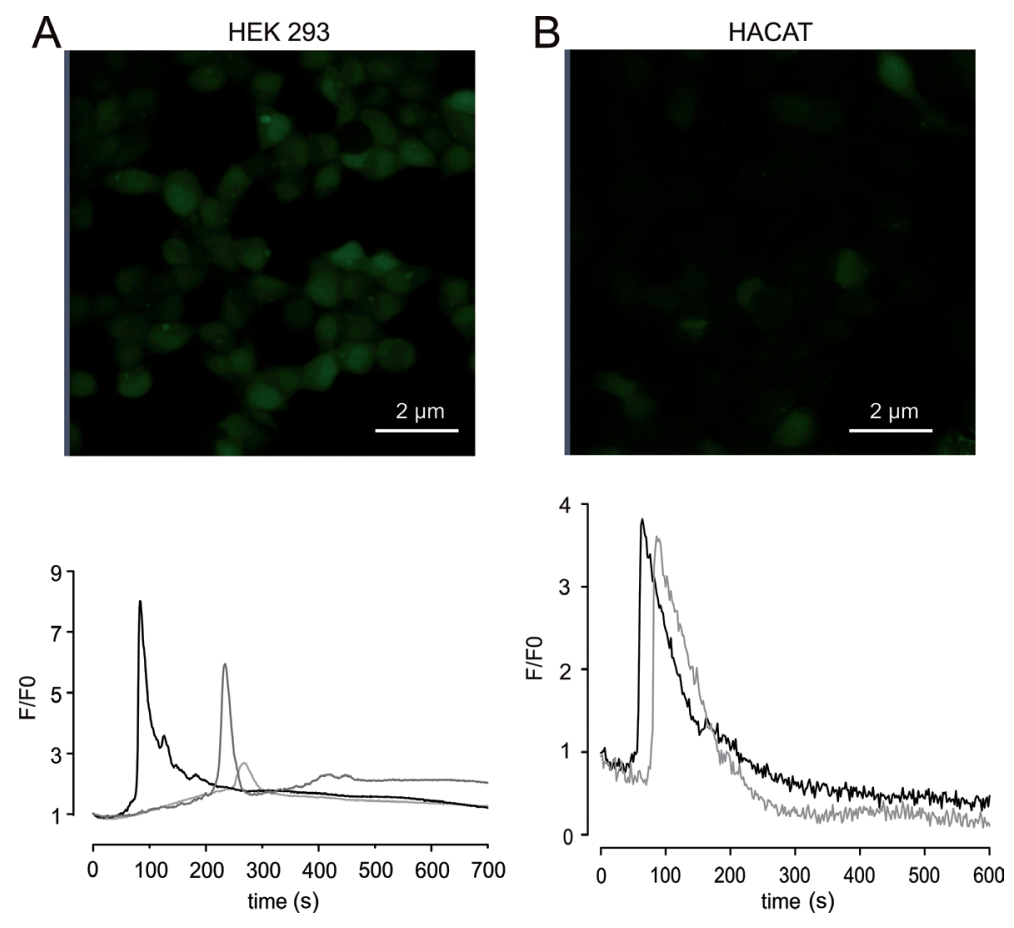

Figure 2. Laser induced fluorescent oscillations in HEK293 cells and HaCaT keratinocytes. Fluorescent images of Fluo-4 loaded ( $2 \mu \mathrm{M}, 30 \mathrm{~min})$ HEK293 cells (A) and HaCaT keratinocytes (B) are shown before imaging (top). Representative fluorescent records using 1\% (for $\mathrm{HaCaT}$ ) and 3\% (for HEK293) laser settings. Different curves represent examples of fluorescence of different cells.

phototoxicity (Grzelak et al. 2001; Dixit and Richard 2003; Knight et al. 2003; Bootman et al. 2013); therefore, we tested the role of ROS in laser-induced fluorescent oscillations by using the ROS scavenger DMPO. Acinar cells were treated with the reagent for 10 minutes before the experiment and cells were continuously perfused with physiological saline solution supplemented with the reducing agent during imaging. Surprisingly, the treatment did not suppress the fluorescent fluctuations, which implies that ROS is not required to generate the oscillatory signal (Figure $3 \mathrm{~A}$ ). This result argues against the hypothesis that ROS mediates fluorescent fluctuations in Fluo-4 loaded cells (Knight et al. 2003).

To clarify whether the laser-induced fluorescence change was really due to $\left[\mathrm{Ca}^{2+}\right]_{\mathrm{i}}$ fluctuations, another $\mathrm{Ca}^{2+}$ indicator was also used for signal detection. For this purpose Fura-Red was chosen because it allows simultaneous Fluo-4 recordings (see Materials and Methods for details) but has very different photochemical properties than Fluo-4. FuraRed is a $\mathrm{Ca}^{2+}$ quenching fluorophore, which means that the increase in $\left[\mathrm{Ca}^{2+}\right]_{\mathrm{i}}$ is reported by a decrease in its emission when excited at $488 \mathrm{~nm}$ (Thomas et al. 2000). Moreover, it is less susceptible to photobleaching and Fura-Red loaded cells show weaker phototoxicity (Rohrbach et al. 2005). Because of these very different optical and chemical characteristics, we assumed that if the oscillations observed in the Fluo-4 signal were not due to changes in the intracellular $\mathrm{Ca}^{2+}$ concentration, Fura-Red should not have reported the change either (Lipp and Niggli 1993). Consequently, if typical Fura-Red responses during laser excitation were detected, it would rather be attributable to changes in $\left[\mathrm{Ca}^{2+}\right]_{\mathrm{i}}$. To test this, cells were co-loaded with Fluo-4 and Fura-Red and the emissions were detected simultaneously (Lipp and Niggli 1993). A representative record of such an experiment is displayed in Figure 3B, showing that the increase in Fluo-4 fluorescence was tightly associated with the decrease in Fura-Red emission.

More importantly, loading cells with the cell permeable $\mathrm{Ca}^{2+}$ chelator BAPTA-AM prevented the fluorescent events (Figure 3C). These results imply that the observed fluorescence fluctuation was due to repetitive changes of $\left[\mathrm{Ca}^{2+}\right]_{i}$.

Next, experiments were designed to identify the source of $\mathrm{Ca}^{2+}$. Exchanging the bath to $\mathrm{Ca}^{2+}$-free saline neither influenced the amplitude, nor the shape of the spikes, whereas spiking was abolished by $2 \mathrm{mM}$ tetracaine (Figure 3D and $\mathrm{E})$, which inhibits $\mathrm{Ca}^{2+}$-release channels in this concentration. These results strongly suggest that $\mathrm{Ca}^{2+}$ was released from the ER.

\section{$\mathrm{Ca}^{2+}$ oscillations on line scan images}

Because the spatio-temporal characteristics of $\mathrm{Ca}^{2+}$ signals are often visualized in line-scan mode, we investigated whether $\mathrm{Ca}^{2+}$-release can be provoked in this mode too, when a single pixel line is excited repetitively at the rate of 500 times per second, at laser intensities ranging from $0.2 \mathrm{~mW}$ to $3 \mathrm{~mW}(2-30 \mu \mathrm{W})$. In Figure $4 \mathrm{~A}-\mathrm{C}$, representative time series line-scan recordings and plots are shown. The scanning line was set across the cell in the apico-basal direction 
(Figure 4A, B, C, left side, yellow lines). The frames used for the selection of the line were always taken using $0.2 \mathrm{~mW}$ laser power output to prevent spontaneous $\mathrm{Ca}^{2+}$ release during the line selection process. Brightness and contrast of the "line select" images were improved after measurement to allow better visibility.

When the line was excited using $3 \mathrm{~mW}$ laser power (Figure 4A), a robust apico-basal $\mathrm{Ca}^{2+}$ wave developed immediately (Figure 4, black line), which was followed by a second one. Importantly, cell morphology only changed (i.e. blebbing developed) $75 \mathrm{~s}$ (37500 line scans) after imaging started (Figure 4A, white arrowhead), much later than the $\mathrm{Ca}^{2+}$-oscillations appeared. In order to prevent obvious signs of phototoxicity and to find the lowest laser power required to elicit the oscillations, laser power was gradually decreased (Figure 4B, C). Although, excitation using $0.2 \mathrm{~mW}$ laser power setting did not cause measurable photobleaching or cell damage, it still elicited significant $\mathrm{Ca}^{2+}$ release (Figure $4 \mathrm{C}$ ). It has to be mentioned that the $0.2 \mathrm{~mW}$ setting is the lowest possible laser emission setting and the 500 FPS is the lowest possible line scanning rate for the model of microscope used and both fell below the typically used settings.

Line scan recordings at high temporal resolution of the apical region of the cells (Figure 5), revealed proportional relationship between the laser power output and the onset of the $\mathrm{Ca}^{2+}$ signal.

\section{Discussion}

Overall, we report an uncommon, but significant methodological problem that exciting laser radiation after conventional Fluo-4-AM loading protocol and microscope settings causes intracellular $\mathrm{Ca}^{2+}$ release. Whilst earlier studies have shown that high illumination levels or sustained illumination can lead to various cytotoxic effects (including $\mathrm{Ca}^{2+}$ transients) (Putney 2007; Smyth et al. 2010), we have demonstrated that in case of our cells even very low levels of excitation and dye-concentration may cause calcium oscillations. We wish to highlight that these setting are well below
A

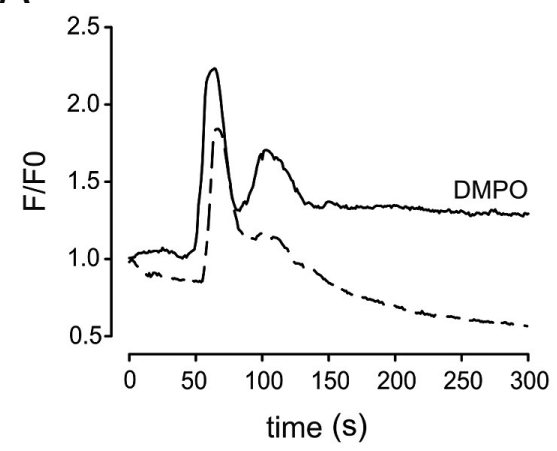

D

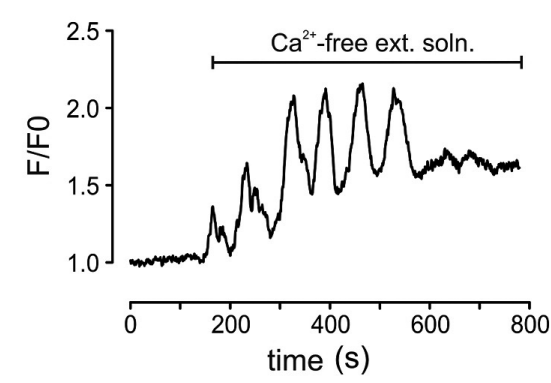

B

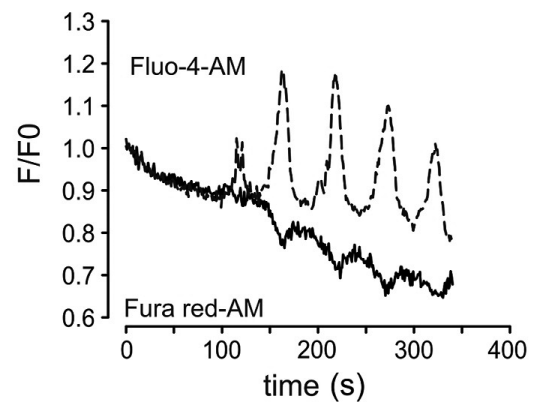

$E$

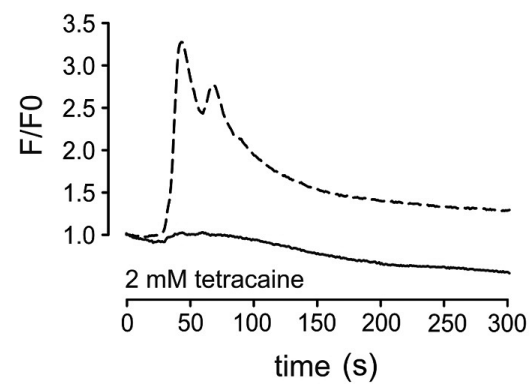

C

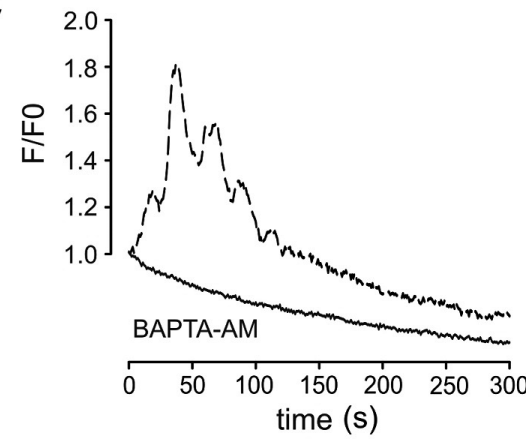

Figure 3. The laser induced fluorescent oscillation is due to $\mathrm{Ca}^{2+}$-release from the ER. Control representative curves are shown with dashed lines and treatments (of different cells) are shown with solid lines. Each line is a representative fluorescence intensity curve of a cell from a run. 3 runs (treatments) were performed for each condition on different groups of cells. A. Fluorescent emissions recorded in pancreatic acinar cells under control conditions and in the presence of the ROS scavenger DMPO. B. Fluorescent oscillations recorded in a cell, which was co-loaded with Fluo-4-AM and Fura-Red-AM. C. The oscillations are abolished by BAPTA-AM treatment. D. Replacing $\mathrm{Ca}^{2+}$ containing extracellular solution to $\mathrm{Ca}^{2+}$-free medium did not influence the oscillatory pattern. E. Tetracaine diminished the laser-induced $\mathrm{Ca}^{2+}$-release. 
the range normally considered safe for imaging $(10-30 \mu \mathrm{W})$. Notably, Knight et al. showed that $488 \mathrm{~nm}$ laser of similar power $(15-30 \mu \mathrm{W})$ induced $\mathrm{Ca}^{2+}$-oscillations in chondrocytes (Knight et al. 2003).

Based on our current data we propose that laser exposure of Fluo- 4 or other dyes in the Fluo-family produces an unknown derivative, which causes $\mathrm{Ca}^{2+}$-release from the ER

A
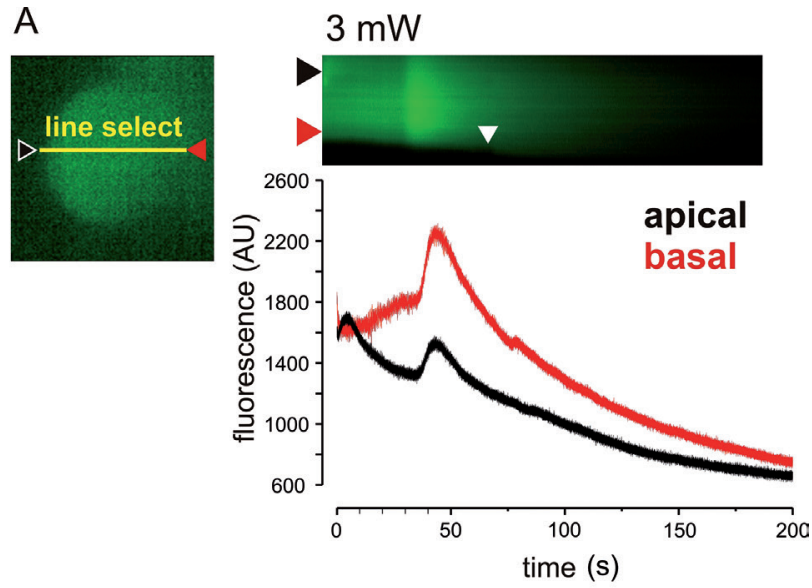

B

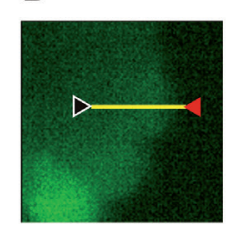

C
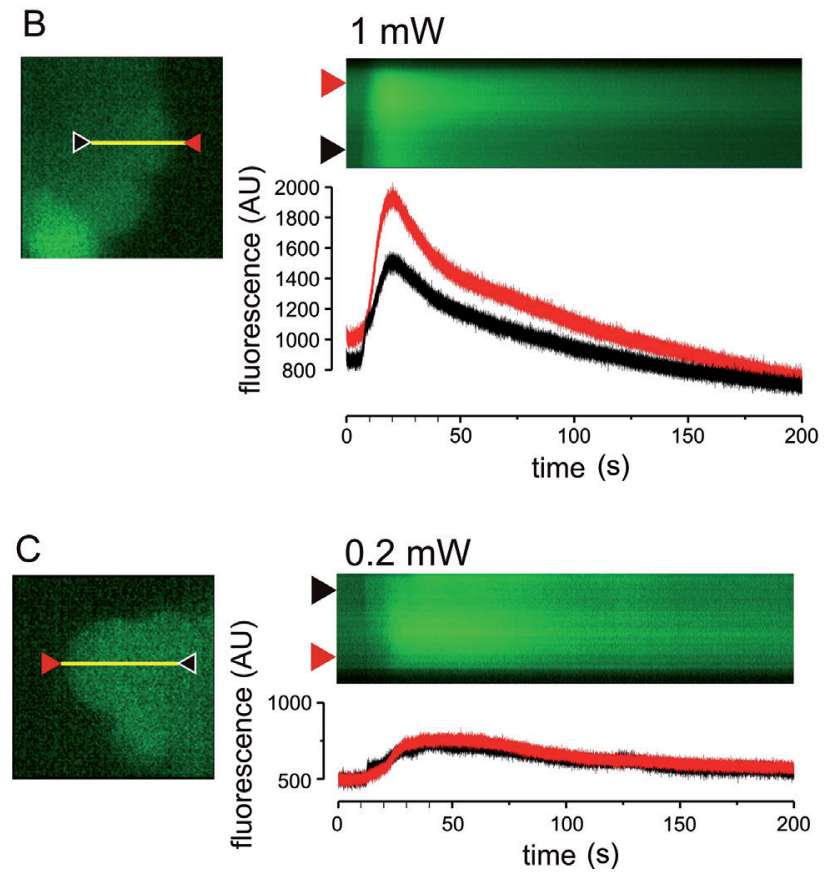

Figure 4. Spatio-temporal characteristics of laser-induced $\mathrm{Ca}^{2+}$ waves in line scan mode. Line scan representative records and plots of cells using $3 \mathrm{~mW}$ (A), $1 \mathrm{~mW}$ (B) and $0.2 \mathrm{~mW}$ (C) laser outputs. The scanning line was placed across the cells in the apico-basal direction, as indicated by the yellow lines. The apical regions of the cells are shown by black, whereas the red arrowheads show the basal regions. The fluorescence changes of these regions are shown by black and red curves, respectively. (See online version for color figure.)

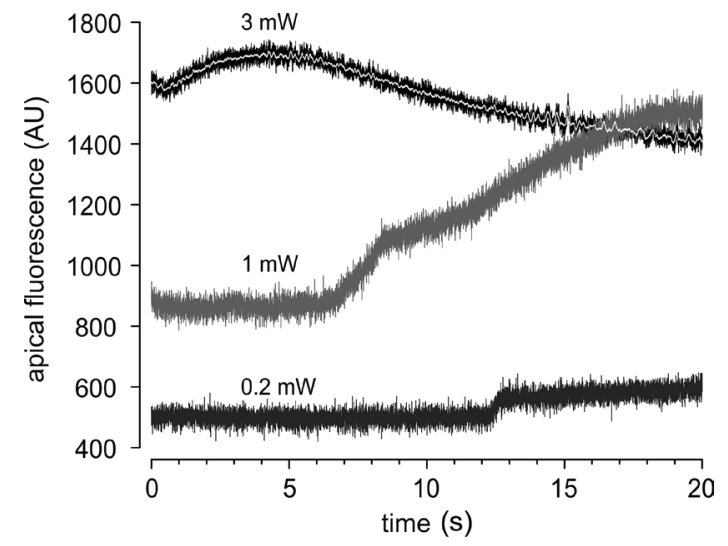

Figure 5. High-resolution plot of the initial response to various levels of laser excitation in line scan mode. The first 20 seconds of apical line scan representative records of Figure 4, where laser power outputs of $3 \mathrm{~mW}$ (black with white centerline), $1 \mathrm{~mW}$ (dark grey) and 0.2 (ligh grey) $\mathrm{mW}$ were used.

by activating $\mathrm{IP}_{3} \mathrm{Rs}$. We found the that the changes in Fluo- 4 fluorescence were due to changes in intracellular $\mathrm{Ca}^{2+}$ levels and the source of $\mathrm{Ca}^{2+}$ was shown to be intracellular, because removing extracellular $\mathrm{Ca}^{2+}$ did not suppress the $\mathrm{Ca}^{2+}$ waves. We have also shown that the amplitude and calcium release kinetics of the laser-induced oscillations in mouse pancreatic acinar cells are comparable to those triggered by 100 or 200 $\mathrm{nM}$ carbachol. The only major intracellular compartment capable of such $\mathrm{Ca}^{2+}$ release is the ER. Although, RyRs are also involved in the $\mathrm{Ca}^{2+}$ release process in pancreatic acinar cells, we tend to blame $\mathrm{IP}_{3} \mathrm{Rs}$ as a culprit to initiate the oscillations, because skeletal muscle fibers that are poor in $\mathrm{IP}_{3}$ Rs but very rich in RyRs, (Fill and Copello 2002) do not show similar laser-induced events (Csernoch 2007). In addition, HEK293 cells were reported to lack endogenous RyR channels, but express $\mathrm{IP}_{3} \mathrm{Rs}$ (Tong et al. 1999; Alzayady et al. 2016).

$\mathrm{Ca}^{2+}$-wave expansion in our cells requires the dynamic cooperation of both, unevenly distributed, but connected parts of the main intracellular $\mathrm{Ca}^{2+}$ compartment, the ER. $\mathrm{IP}_{3} \mathrm{Rs}$ are primarily located in the apical ER, whereas RyRs can be found throughout the ER, but most abundantly in the supranuclear-basal region. Therefore, physiological secretagogue stimulation causes $\mathrm{Ca}^{2+}$ waves that are always initiated by $\mathrm{IP}_{3} \mathrm{R}$ activation on the apical side of the ER and propagate towards the basal end via CICR (Petersen 2005, 2014; Petersen and Tepikin 2008). The intracellular $\mathrm{Ca}^{2+}$ dynamics of laser-induced oscillations are very similar to those of secretagogue-induced responses, further suggesting the major role of $\mathrm{IP}_{3} \mathrm{Rs}$ in the process. The apico-basal propagation of calcium signal suggests the involvement of $\mathrm{IP}_{3} \mathrm{Rs}$ in the initiation of the light-activated calcium signal. In Figure 5, the stepwise increase of $\mathrm{Ca}^{2+}$-level on the apical 
side of cells triggered by 0.2 and $1 \mathrm{~mW}$ laser power suggests that the waves might be formed by a multi-step process. This can be explained by the sequential opening of $\mathrm{Ca}^{2+}$ channels or the exhaustion of $\mathrm{Ca}^{2+}$-buffering capacity of the apical portion of the cell.

The current study initially investigated the mechanism of light-induced artifacts in mouse pancreatic acinar cells, but later revealed that the problem is not limited to this cell type and looks to be a general phenomenon.

It should be highlighted that decreasing Fluo-loading may not offer an adequate strategy to avoid laser-induced $\mathrm{Ca}^{2+}$ release in all cells because it compromises the signal to noise ratio (the resting fluorescence at $1 \mathrm{~mW}$ was already only 3 times higher than the background). Instead, we suggest finding the balance by minimizing both the level of dye loading and the cumulative incident light intensity by using low imaging rate with the lowest light intensity and dwell time possible. It must also be noted that in case of line-scan imaging we could not prevent the formation of light-induced $\mathrm{Ca}^{2+}$ release even at the lowest possible excitation level and lowest dye-loading.

In conclusion, during laser-scanning microscopy possible artifacts due to laser excitation should be taken into account, even when low power settings are used and in some cases laser scanning methods may not be useable for calcium imaging.

Acknowledgements. This work was supported by a grant provided to JA from the Hungarian Scientific Research Fund (OTKA PD 112199). This research was supported by the European Union and the State of Hungary, co-financed by the European Social Fund in the framework of TÁMOP-4.2.4.A/2-11/1-2012-0001 'National Excellence Program' (JV). JA is supported by the Janos Bolyai Research Scholarship of the Hungarian Academy of Sciences and the Lajos Szodoray Scholarship of the University of Debrecen.

\section{References}

Alzayady KJ, Wang L, Chandrasekhar R, Wagner LE, Van Petegem F, Yule DI (2016): Defining the stoichiometry of inositol 1,4,5-trisphosphate binding required to initiate $\mathrm{Ca} 2+$ release. Sci. Signal. 9, 422 https://doi.org/10.1126/scisignal.aad6281

Bootman MD, Rietdorf K, Collins T, Walker S, Sanderson M (2013): $\mathrm{Ca} 2+$ sensitive fluorescent dyes and intracellular $\mathrm{Ca} 2+$ imaging. Cold Spring Harb Protoc. 2, 83-89 https://doi.org/10.1101/pdb.top066050

Collins T, Walker S, Sanderson M (2014): Ca2+-sensitive fluorescent dyes and intracellular $\mathrm{Ca} 2+$ imaging. In: Calcium techniques: A laboratory manual. (Eds. MD Bootman and K Rietdorf), pp. 42-46, Cold Spring Harbor Laboratory Press

Csernoch L (2007): Sparks and embers of skeletal muscle: the exciting events of contractile activation. Pflugers Arch. 454, 869-878 https://doi.org/10.1007/s00424-007-0244-0
Dixit R, Richard C (2003): Cell damage and reactive oxygen species production induced by fluorescence microscopy: effect on mitosis and guidelines for non-invasive fluorescence microscopy. Plant J. 36, 280-290 https://doi.org/10.1046/j.1365-313X.2003.01868.x

Fedoryak OD, Searls Y, Smirnova IV, Burns DM, Stehno-Bittel L (2004): Spontaneous Ca2+ oscillations in subcellular compartments of vascular smooth muscle cells rely on different $\mathrm{Ca} 2+$ pools. Cell Research 14, 379-388 https://doi.org/10.1038/sj.cr.7290238

Fill M, Copello JA (2002): Ryanodine receptor calcium release channels. Phys. Rev. 82, 893-922 https://doi.org/10.1152/physrev.00013.2002

Gee KR, Brown KA, Chen WN, Bishop-Stewart J, Gray D, Johnson I (2000): Chemical and physiological characterization of fluo-4 Ca2+-indicator dyes. Cell Calcium 27, 97-106 https://doi.org/10.1054/ceca.1999.0095

Geyer N, Diszházi G, Csernoch L, Jóna I, Almássy J (2015): Bile acids activate ryanodine receptors in pancreatic acinar cells via a direct allosteric mechanism. Cell Calcium 58, 160-170 https://doi.org/10.1016/j.ceca.2015.03.009

Grzelak A, Rychlik B, Bartosz G (2001): Light-dependent generation of reactive oxygen species in cell culture media. Free Radic. Biol. Med. 30, 1418-1425 https://doi.org/10.1016/S0891-5849(01)00545-7

Habara Y, Kanno T (1994): Stimulus-secretion coupling and Ca2+ dynamics in pancreatic acinar cells. Gen. Pharmac. 25, 843-850 https://doi.org/10.1016/0306-3623(94)90085-X

Hoebe RA, van Oven CH, Gadella TWJ, Dhonukshe PB, van Noorden CJF, Manders EMM (2007): Controlled light-exposure microscopy reduces photobleaching and phototoxicity in fluorescence live-cell imaging. Nat. Biotechnol. 25, 249-253 https://doi.org/10.1038/nbt1278

Johnston L, Sergeant GP, Hollywood MA, Thornbury KD, McHale NG (2005): Calcium oscillations in interstitial cells of the rabbit urethra. J. Physiol. 565, 449-461 https://doi.org/10.1113/jphysiol.2004.078097

Knight MM, Roberts SR, Lee DA, Bader DL (2003): Live cell imaging using confocal microscopy induces intracellular calcium transients and cell death. Am. J. Physiol. Cell Physiol. 284, 1083-1089 https://doi.org/10.1152/ajpcell.00276.2002

Leite MF, Burgstahler AD, Nathanson MH (2002): Ca2+ waves require sequential activation of inositol trisphosphate receptors and ryanodine receptors in pancreatic acini. Gastroenterology 122, 415-427

https://doi.org/10.1053/gast.2002.30982

Lewis RS (2007): The molecular choreography of a store-operated calcium channel. Nature 446, 284-287

https://doi.org/10.1038/nature05637

Lipp P, Niggli E (1993): Ratiometric confocal Ca2+-measurements with visible wavelength indicators in isolated cardiac myocytes. Cell Calcium 5, 359-372 https://doi.org/10.1016/0143-4160(93)90040-D

McDonald A, Harris J, MacMillan D, Dempster J, McConnell G (2012): Light-induced Ca2+ transients observed in widefield epi-fluorescence microscopy of excitable cells. Biomed. Opt. Express 3, 1266-1273 
https://doi.org/10.1364/BOE.3.001266

Minta A, Kao JP, Tsien RY (1989): Fluorescent indicators for cytosolic calcium based on rhodamine and fluorescein chromophores. J. Biol. Chem. 264, 8171-8178

Papp H, Czifra G, Lázár J, Gönczi M, Csernoch L, Kovács L, Bíro T (2003): Protein kinase C isozymes regulate proliferation and high cell density-mediated differentiation in $\mathrm{HaCaT}$ keratinocytes. Exp. Dermatol. 12, 811-824 https://doi.org/10.1111/j.0906-6705.2003.00097.x

Pawley J (2006): Handbook of Biological Confocal Microscopy. Springer, New York https://doi.org/10.1007/978-0-387-45524-2

Petersen $\mathrm{OH}$ (2005): Ca2+ signaling and Ca2+-activated ion channels in exocrine acinar cells. Cell Calcium 38, 171-200 https://doi.org/10.1016/j.ceca.2005.06.024

Petersen OH (2014): Calcium signalling and secretory epithelia. Cell Calcium 56, 282-289 https://doi.org/10.1016/j.ceca.2014.01.003

Petersen OH, Tepikin VA (2007): Polarized calcium signaling in exocrine gland cells. Annu Rev. Physiol. 70, 273-299 https://doi.org/10.1146/annurev.physiol.70.113006.100618

Petersen OH, Tepikin AV (2008): Polarized calcium signaling in exocrine gland cells. Annu Rev. Physiol. 70, 273-299 https://doi.org/10.1146/annurev.physiol.70.113006.100618

Putney JW (2007): New molecular players in capacitative Ca2+ entry. J. Cell Sci. 120, 1959-1965 https://doi.org/10.1242/jcs.03462

Rohrbach P, Friedrich O, Hentschel J, Plattner H, Fink RHA, Lanzer M (2005): Quantitative calcium measurements in subcellular compartments of Plasmodium falciparum-infected erythrocytes. J. Biol. Chem. 280, 27960-27969 https://doi.org/10.1074/jbc.M500777200

Smyth JT, Hwang SY, Tomita T, DeHaven WI, Mercer JC, Putney JW (2010): Activation and regulation of store-operated calcium entry. J. Cell Mol. Med. 14, 2337-2349 https://doi.org/10.1111/j.1582-4934.2010.01168.x

Straub SV, Giovannucci DR, Yule DI (2000): Calcium wave propagation in pancreatic acinar cells. Functional interaction of inositol 1,4,5-trisphosphate receptors, ryanodine receptors and mitochondria. J. Gen. Physiol. 116, 547-560 https://doi.org/10.1085/jgp.116.4.547

Thomas D, Tovey SC, Collins TJ, Bootman MD, Berridge MJ, Lipp $\mathrm{P}$ (2000): A comparison of fluorescent $\mathrm{Ca} 2+$ indicator properties and their use in measuring elementary and global Ca2+ signals. Cell Calcium 28, 213-223 https://doi.org/10.1054/ceca.2000.0152

Tong J, Du GG, Chen SR, MacLennan DH (1999): HEK-293 cells possess a carbachol- and thapsigargin-sensitive intracellular $\mathrm{Ca} 2+$ store that is responsive to stop-flow medium changes and insensitive to caffeine and ryanodine. Biochem. J. 343, 39-44 https://doi.org/10.1042/bj3430039

Yule DI (2015): Ca2+ signaling in pancreatic acinar cells. Pancreapedia: Exocrine Pancreas Knowledge Base

Vukcevic M, Zorzato F, Spagnoli G, Treves S (2010): Frequent calcium oscillations lead to NFAT activation in human immature dendritic cells. J. Biol. Chem. 285, 16003-16010 https://doi.org/10.1074/jbc.M109.066704

Wang T, Zhou C, Tang A, Wang S, Chai Z (2006): Cellular mechanism for spontaneous calcium oscillations in astrocytes. Acta Pharmacol. Sin. 27, 861-868 https://doi.org/10.1111/j.1745-7254.2006.00397.x

Williams JA, Korc M, Dormer RL (1978): Action of secretagogues on a new preparation of functionally intact isolated pancreatic acini. Am. J. Physiol. 235, 517-524 https://doi.org/10.1152/ajpendo.1978.235.5.E517

Received: September 2, 2017

Final version accepted: November 2, 2017

First published online: March 28, 2018 


\section{Supplementary Material}

\section{Laser induced calcium oscillations in fluorescent calcium imaging}

János Vincze ${ }^{1, \star}$, Nikolett Geyer ${ }^{1, \star}$, Gyula Diszházi ${ }^{1}$, László Csernoch ${ }^{1}$, Tamás Bíró ${ }^{2}$, István Jóna ${ }^{1}$, Beatrix Dienes ${ }^{1}$ and János Almássy ${ }^{1}$

1 Department of Physiology, University of Debrecen, Faculty of Medicine, 98. Nagyerdei krt., Debrecen 4012, Hungary

2 Departments of Immunology, University of Debrecen, Faculty of Medicine, 98. Nagyerdei krt., Debrecen 4012, Hungary

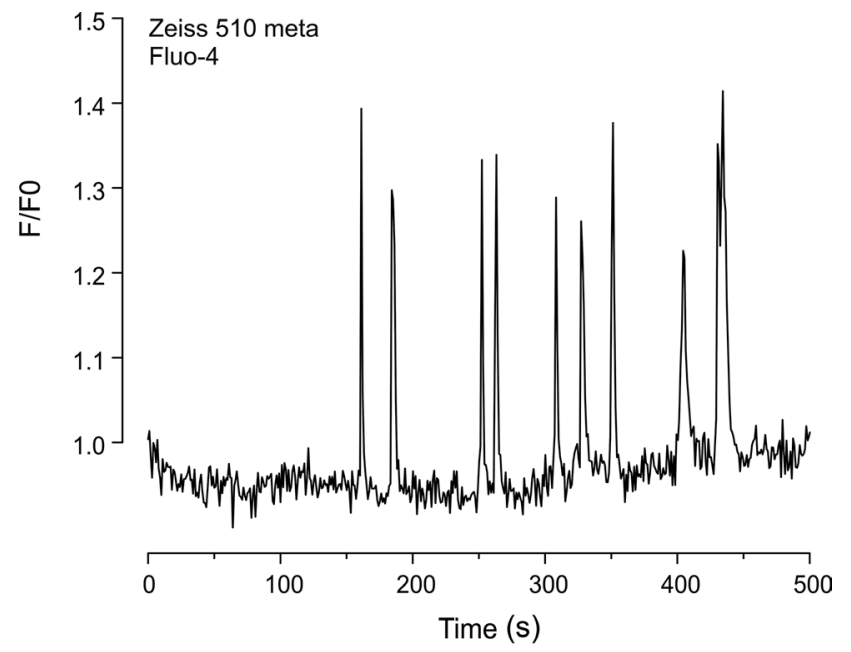

Figure S1. Laser emission-evoked fluorescent oscillations in Fluo-4 AM-loaded pancreatic acinar cells.

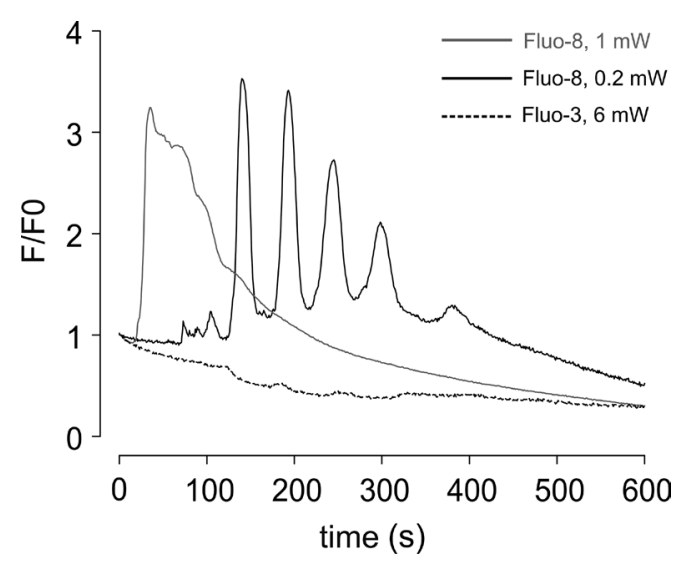

Figure S2. Laser emission-evoked fluorescent oscillations in Fluo-3 and 8 AM-loaded pancreatic acinar cells. 